\title{
APLIKASI RUNNING TEXT BERUPA JADWAL SHOLAT 5 WAKTU PADA MUSHOLLA POLMAN NEGERI BANGKA BELITUNG
}

\author{
Aan Febriansyah ${ }^{1}$, Iskandar ${ }^{2}$, Bayu Cahyawan ${ }^{3}$, Dian Kusuma Negara ${ }^{4}$ \\ Politeknik Manufaktur Negeri Bangka Belitung-Jurusan Teknik Elektro dan Informatika \\ Kawasan Industri Air Kantung Sungailiat - 33211 Telp. (0717) 93586, Fax. (0717) 93585 \\ aan9277@gmail.com
}

\begin{abstract}
In Islam, prayer is an obligation that must be carried out by any of its adherents who already qualified. In one day and one night there are five time prayers, namely Isya, Dawn, Noon, Asr and Maghrib. One of the greatest deeds reward is prayer in congregation at mosques or mosque at the time it was signed in prayer. Usually several mosques or mosque own marker arrival time of prayer are created automatically, making it easier for the muezzin to call the adhan. However it was still a small fraction. There are still many mosques or mosques who do not have means of automatic prayer time this marker. For that know the times of prayer 5 times a day is very important for any religion in the Islamic prayer run the 5 time period with a precise and well. To that end pointer prayer schedule is very important that there. So now many mosques or in homes that are usually already contained a calendar and prayer time enduring performer, but it looks very small so it cannot be seen from a distance. Based on that experience and the importance of this, the authors do make the viewer prayer time in real time that can change with the change of the day, and can be seen from a considerable distance. So that it can function more optimally and can maximize the time available.
\end{abstract}

Keywords: Schedule, Prayer 5 times, Running Text, Microcontroller

\begin{abstract}
Abstrak
Dalam agama Islam, sholat merupakan kewajiban yang harus dikerjakan oleh setiap pemeluknya yang sudah memenuhi syarat. Dalam satu hari satu malam terdapat lima waktu sholat, yaitu Isya, Subuh, Zuhur, Ashar, dan Maghrib. Salah satu amalan yang paling besar pahalanya adalah sholat berjamaah di masjid atau musholla pada saat sudah masuk waktu sholat. Biasanya beberapa masjid atau musholla sudah memiliki penanda datangnya waktu sholat yang dibuat secara otomatis, sehingga memudahkan muadzin untuk menyerukan adzan. Namun itu masih sebagian kecil saja. Masih banyak masjid atau musholla yang belum memiliki sarana penanda waktu sholat otomatis ini. Untuk itu mengetahui waktu shalat 5 waktu sangatlah penting bagi setiap pemeluk agama islam agar dapat menjalankan shalat 5 waktu tersebut dengan tepat dan sebaik-baiknya. Oleh karena itu penanda jadwal shalat itu sangat penting adanya. Maka sekarang ini banyak di masjid maupun di rumah-rumah yang biasanya sudah terdapat kalender maupun penampil waktu sholat abadi, akan tetapi tampilannya sangat kecil sehingga tidak dapat dilihat dari jarak jauh. Berdasarkan dari pengalaman itu dan pentingnya hal ini maka penulis membuat penampil waktu sholat yang dapat secara real time berubah mengikuti perubahan hari, dan dapat dilihat dari jarak yang cukup jauh. Sehingga dapat lebih berfungsi optimal serta dapat memaksimalkan waktu yang ada.
\end{abstract}

Kata kunci: Jadwal, Sholat 5 Waktu, Running Text, Mikrokontroler

\section{PENDAHULUAN}

Untuk itu mengetahui waktu shalat 5 waktu, yaitu subuh, dzuhur, asar, magrib, dan isya sangatlah penting bagi setiap pemeluk agama islam didalam menjalakan shalat 5 waktu tersebut dengan tepat dan sebaik-baiknya. Untuk itu penunjuk jadwal shalat itu sangat penting akan adanya. Maka, 
sekarang ini banyak di masjid maupun di rumah-rumah yang biasanya sudah terdapat kalender maupun penampil waktu sholat abadi, akan tetapi tampilannya sangat kecil sehingga tidak dapat dilihat dari jarak jauh. Untuk itu diperlukan cara bagaimana merancang sistem kontrol penanda datangnya waktu sholat untuk 5 waktu tersebut agar selalu sesuai dengan jadwal sholat yang ada di wilayah Bangka, dan berjalan secara otomatis seiring berjalannya waktu dari hari ke minggu, dan seterusnya hingga berganti tahun, tanpa perlu diatur manual. Selain itu juga diperlukan cara bagaimana membuat tampilan dan penanda dengan mode yang dinamis dan menarik yang dapat dilihat dari jarak tertentu, agar waktu sholat dapat terbaca oleh jemaah yang hadir.

Pada rancangan penelitian ini kami menggunakan mikrokontroller ATMega sebagai otak dari sistem, membaca data base EEPROM, membaca RTC kemudian menampilkan pada display Dot Matriks LED. Push button berfungsi sebagai ON/OFF dan juga untuk tombol buzzer. RTC berfungsi sebagai pengitung detak-detak jam, yang datanya digunakan sebagai acuan dalam penentuan pada kalender, jam digital. EEPROM berfungsi sebagai memori external [1], terutama untuk penyimpanan data base jadwal solat. Dot Matriks LED berfungsi sebagai penampil data-data yang dihasilkan oleh mikrokontroller menjadi tampilan tangal, jam, serta waktu solat. Buzzer berfungsi sebagai penanda masuk waktu iqomah. Secara garis besar, Gambar 1 merupakan skema penelitian yang akan dilakukan.

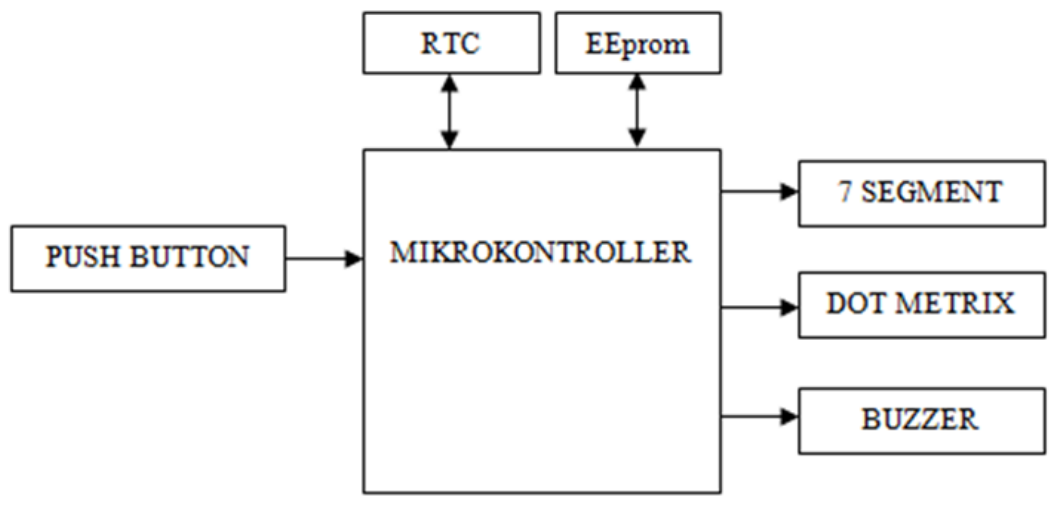

Gambar 1. Perancangan Skema Sistem Kontrol Alat

\section{METODE PENELITIAN}

Riset akan berfokus pada bagaimana merencanakan, merancang dan membuat alat agar sesuai dengan tujuan yang diinginkan. Dalam pelaksanaan penelitian ini, dilakukan tahapan-tahapan penelitian yang bertujuan untuk memudahkan penulis dalam proses pembuatan alat. Untuk mencapai beberapa fungsi dan spesifikasi tersebut, maka dilakukan beberapa tahap metode [2], antara lain:

\subsection{Tahap Persiapan/Perencanaan}

Pada tahap persiapan dilakukan pengamatan dan penelitian mengenai alat yang akan dirancang dan dibuat. Selanjutnya dari hasil pengamatan dan penelitian nantinya dilakukan perbandingan untuk menentukan perencanaan mengenai produk atau alat yang akan dibuat serta tujuan pembuatan.

\subsection{Metode Pengumpulan Data}

Pengumpulan data ini berfungsi untuk mengetahui kebutuhan-kebutuhan teknologi tentang suatu jenis alat atau mencari kemungkinan-kemungkinan untuk melakukan modifikasi terhadap alat yang telah ada. Data yang telah terkumpul nantinya akan dimasukkan dalam penulisan makalah sebagai landasan dalam pembuatan alat tersebut. Metode pengumpulan data yang diterapkan antara lain:

a. Studi Pustaka (studi literatur)

Untuk menunjang dalam pembuatan riset ini, data dari berbagai sumber yang terkait dengan masalah-masalah yang akan dibahas dikumpulkan. Data-data tersebut didapatkan melalui beberapa buku dan internet.

b. Konsultasi kepakaran

Metode pengumpulan data untuk mendukung metode pemecahan masalah, dari pakar-pakar dan pihak-pihak lain agar tujuan yang diharapkan dapat tercapai. 


\subsection{Desain Pembuatan Alat}

Tahap ini merupakan inti dari kegiatan riset yang dilakukan. Perancangan ini mencakup konsep rangkaian inti dan pendukung, serta bentuk kemasan produk yang akan dibuat.

\subsection{Pembuatan Rangkaian Hardware}

Perancangan rangkaian hardware ini dibuat setelah adanya pengambilan keputusan tentang pemilihan komponen dan rangkaian yang tepat untuk dipakai pada alat ini. Untuk mencapai kapasitas tersebut harus dilakukan pengujian dan percobaan yang terintegrasi menggunakan instrumentasi elekrik yang presisi.

\section{HASIL DAN PEMBAHASAN}

Secara umum, kegiatan riset ini memiliki fokus rancangan hardware dan software. Tingkat keberhasilan ketercapaian tujuan dalam penelitian ini adalah 85 - 90\%. Gambar 3 menunjukkan blok diagram pembuatan alat secara keseluruhan.

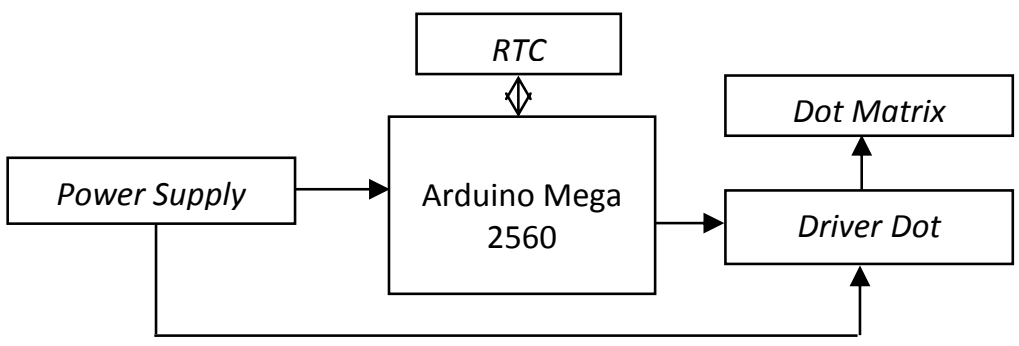

Gambar 3. Blok Diagram Sistem Keseluruhan

\subsection{Perancangan dan Pembuatan Dot Matrix Beserta Ukuran Box Panelnya}

Pada penelitian ini dibutuhkan dot matrix berukuran $100 \times 20 \mathrm{~cm}$. Untuk mendapatkan dot matrix sebesar itu sangat sulit. Selain itu dibutuhkan biaya yang lebih besar. Oleh karena itu, panel dot matrix dibuat dari susunan LED yaitu untuk setiap 1 blok terdiri dari 8 baris x 24 kolom yang membutuhkan 384 buah LED. Pada penelitian ini dibuat 4 blok rangkaian LED yang sama. Pada pembuatan dot matrix menggunakan rangkaian yang telah dirancang sebelumnya. Dengan total LED yang digunakan sebanyak 1536. Setiap kolom mempunyai hambatan sebesar $220 \mathrm{Ohm}$, sehingga dengan tegangan 5 volt DC, diperoleh arus sebesar 0,022 ampere, perhitungan sebagai berikut [3]:

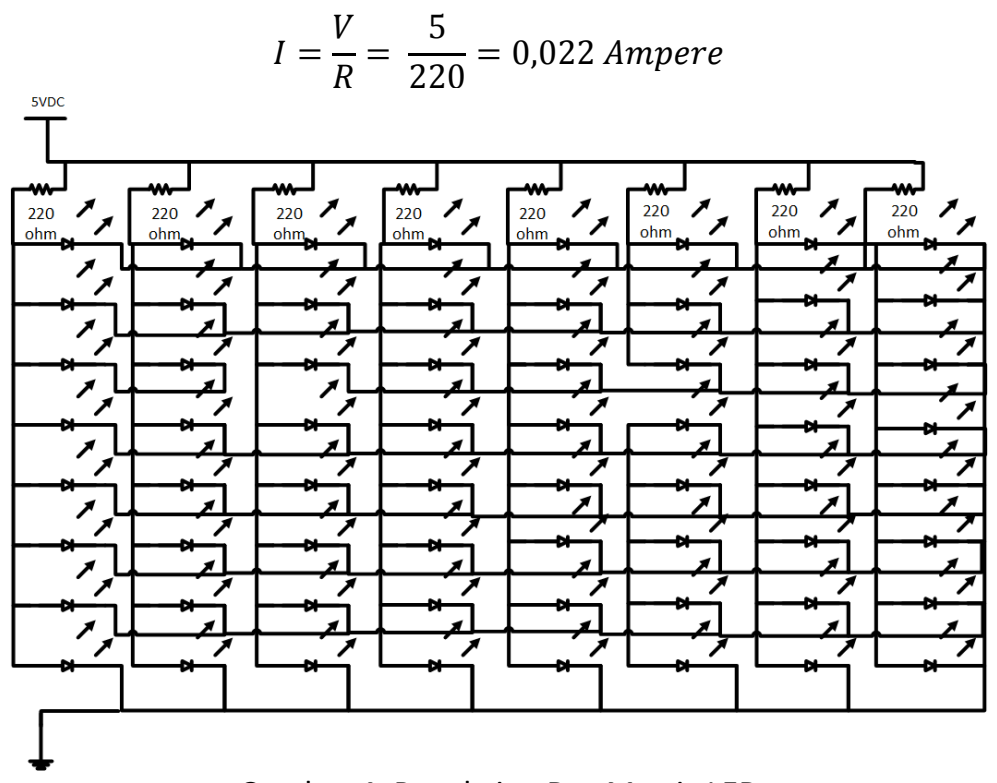

Gambar 4. Rangkaian Dot Matrix LED 
Dot matrik yang digunakan terdiri dari 2 bagian. Setiap segmen terdiri dari 96 kolom yang terbagi oleh 12 shift register. Shift register mengeluarkan output perkolom. Jadi arus yang mengalir pada keseluruhan adalah [4]:

Arus setiap bagian adalah $\quad=(0.022 \mathrm{~A} \times 12)+40 \mathrm{~mA}$ (arus arduino)

Arusl total

$$
=0.314 \mathrm{~A} \text {, sehingga }
$$$$
=0.312 \times 2 \text { bagian }
$$

$=0.624$ Ampere

Untuk perhitungan daya yang terjadi pada rangkaian dot matrix dapat diselesaikan dengan rumus berikut:

$$
\begin{array}{ll}
\text { Daya pada dot matrix } & =\mathrm{V} \times \mathrm{I} \text { total } \\
& =5 \mathrm{~V} \times 0.624 \mathrm{~A} \\
& =3.12 \mathrm{Watt}
\end{array}
$$

\subsection{Perancangan Driver Dot Matrix}

Keluaran dari arduino mega tidak bisa memberi supply tegangan ke dot matrix secara langsung. Hal ini disebabkan karena arus keluaran dari arduino terlalu kecil untuk mengaktifkan dot matrix yang berukuran besar. Oleh karena itu, untuk mengatasinya dibutuhkan rangkaian driver yang mampu memenuhi kebutuhan arus yang dibutuhkan dot matrix. Rangkaian driver yang digunakan untuk dot matrix adalah rangkaian yang menggunakan IC shift register 74HC595 [5]. Fungsi dari shift register adalah untuk menggeser kolom tiap karakter dari dot matrix, yaitu dengan menggeser bit 0 yang berasal dari arduino. Scrolling text pada dot matrix ini menggunakan IC 74HC595 sebagai shift register untuk mengatur kolom (Driver kolom). Berikut ini adalah contoh program program untuk menampilkan huruf dan angka pada dot matrix [6]:

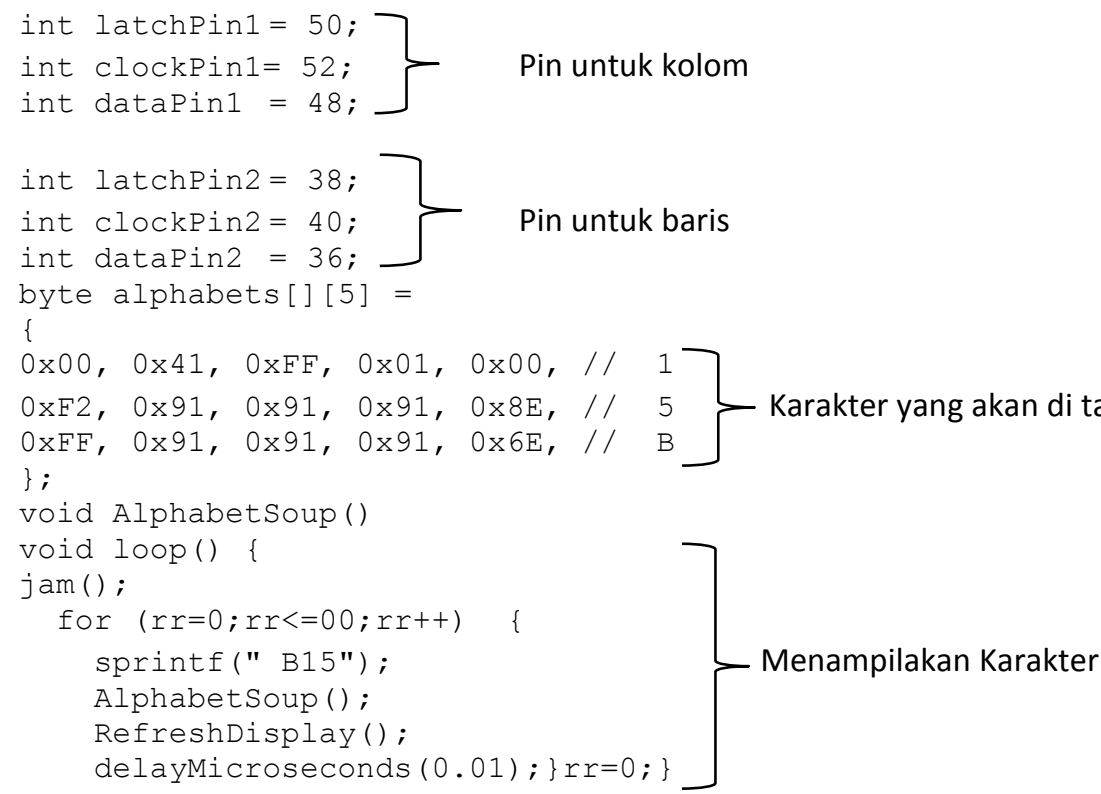

Hasil uji program dapat dilihat pada Gambar 5.

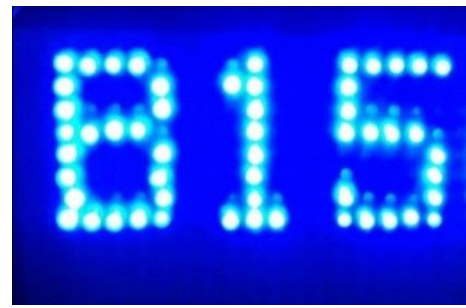

Gambar 5. Pengujian Rangkaian Driver dan Program Dot Matrix 


\subsection{Perancangan Pemrograman Keseluruhan}

Flowchart dibuat sebelum melakukan permrograman Flowchart ini diperlukan untuk memudahkan pada saat pemrograman. Gambar 6 menunjukkan flowchart pemrograman jadwal sholat.

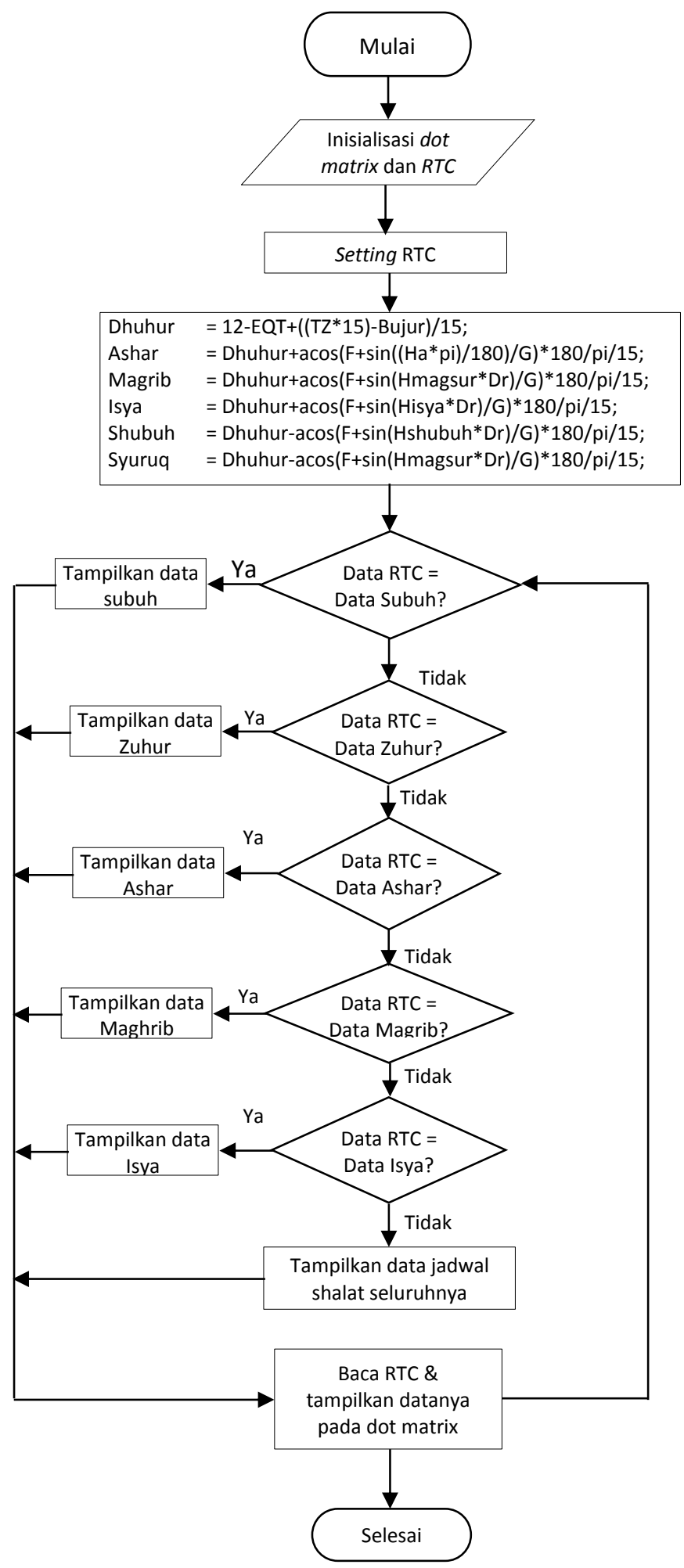

Gambar 6. Flowchart Program 


\section{SIMPULAN}

Hasil utama riset yang diperoleh sebagai berikut:

1. Jadwal sholat yang digunakan adalah jadwal sholat sepanjang masa dengan menggunakan local time yang dapat diseting sesuai dengan wilayah dengan tingkat kepresisian \pm 1 menit.

2. Masing-masing bagian dot matriks memiliki kontrol masing-masing yang dapat diatur secara terpisah maupun secara kesatuan menyeluruh.

3. Pemrograman terhadap jadwal sholat menggunakan Mikrokontroler Arduino.

\section{DAFTAR PUSTAKA}

[1]. Mike Tooley, (2003), Rangkaian Elektronik: Prinsip dan Aplikasi, Erlangga, Jakarta.

[2]. Sugiyono, (2011), Metode Penelitian Kuantitatif Kualitatif dan R\&D, Bandung: Alfabeta.

[3]. Morris, A.S, (2001), Measurement and Instrumentation Principles, British Library Cataloguing in Publication Data, ISBN 0750650818.

[4]. Wasito S, (2001), Vademekum Elektronika (Edisi 2), Gramedia, Jakarta.

[5]. Direct Industry, 2006, Digital ohmmeter/micro. diakses pada 2 April 2015, $<$ http://www.directindustry.com>.

[6]. Enertech Devices, 2012, Digital Voltmeter. diakses pada 6 April 2015, <http:// http://www.enertechdevices.com/products/digital_voltmeter_48_X_96.php> 